\title{
POMEGRANATE FRUIT DISEASES DETECTION USING IMAGE PROCESSING TECHNIQUES: A REVIEW
}

\author{
Jayashri Patil ${ }^{1}$, Sachin Naik ${ }^{2}$ \\ ${ }^{1}$ Research scholar at Symbiosis Institute of Computer Studies and Research (SICSR), Symbiosis International University (Deemed \\ University) Pune, Maharashtra State, India \\ ${ }^{2}$ Assistant Professor at Symbiosis Institute of Computer Studies and Research (SICSR), Symbiosis International University \\ (Deemed University) Pune, Maharashtra State, India \\ Email: ${ }^{1}$ jayashrimadane@gmail.com, ${ }^{2}$ sachin.naik@sicsr.ac.in
}

\begin{abstract}
The Agriculture plant diseases are responsible for farmer economic losses. These diseases affect on plant root, fruit, leaf, and stem. Detection of disease at early stages helps the farmer to improve productivity. In the traditional system agriculture experts and experienced farmer can recognize the plant diseases at the lower accuracy which causes losses to farmers. Currently several researchers are proposing soft computing and expert systems to recognize plant diseases. Plant disease identification by visual way is less accurate because some diseases do not have any visible symptoms or some of the diseases appear too late at the time of harvesting. The modern technology in agriculture sector can substantially improve the agriculture production \& sustainability. This paper provides a review for fruit disease detection techniques for pomegranate plants. This study includes preprocessing, segmentation, feature extraction and classification techniques for pomegranate fruit diseases detection systems. This paper also states the comparison and limitations of existing fruit disease detection techniques.
\end{abstract}

Keywords: Plant disease detection, Classification, Feature extraction, segmentation, pre-processing, SVM

\section{Introduction}

Fruit agriculture play important role in every country economy. In India agricultural practices carried out in traditional manner. Agriculture has become uncertain with weather, water scarcity and pesticides are the major player in it. In 21 st Century to compete the world the improved and advanced techniques should be used and implemented in farming. Developing country like India there is need of adapting new technology for increase the yield of farmer meet to requirement of customer also financial growth of farmers.

In agriculture every crop need proper management of fertilizer, irrigation, pesticides and early disease detection. Modern technology is playing important role in development of country. To achieve the highest economic growth of farmer there is need of adoption of modern technology for sustainable farming system. It is hard to detect and classify the types of disease and pests which cannot be detected by farmer. Only agriculture expert or very experienced farmers can know the type of diseases and pests on plant. So, farmers have to invite the agriculture expert to their farms or farmers need take the sample from the farm to agriculture research center. Diseases are responsible for economic, social and ecological losses. These diseases need to be control at initial stage of infection. Some of the diseases very hard to control in next stage of infection. Plant disease detection system first capturing image by image sensor devices, preprocessing technique on diseased plant leaf or fruit image, Split the image into different segments using segmentation technique, feature selection and extraction, fruit or leaf disease identification using classification. The plant leaf, fruit or stem are main visual parts of plant shown the disease symptoms. Therefore use of soft computing technique to find and classify diseases in agricultural applications is useful. Pomegranate is one of the commercial and drought tolerant crops. Pomegranate growers are essential part of the agriculture sector in India where they present significant share in agriculture economy. Pomegranate Belongs to the family of Punicaceae [1] with botanical name Punica granatum L., As per Report of National Horticulture Board of India are of pomegranate cultivation is an increasing from 2014-15 to 2018-19; similarly, the productivity has decreased from 12.15 (MT/HA) to $11.64(\mathrm{MT} / \mathrm{HA})$ thousand tons during the same period. Pomegranate farmers are suffering from low productivity and low quality. [Source: Horticultural Statistics at a Glance, 2017].

\section{Pomegranate Plant Diseases}

Pomegranate plants get affected by fungi, Bacteria and pests every year. Pomegranate farmer facing a huge damage because of these diseases. Due to these diseases $60 \%$ pomegranate plant may die in the field. This section describes Pomegranate plants get affected by fungi, Bacteria and virus. 


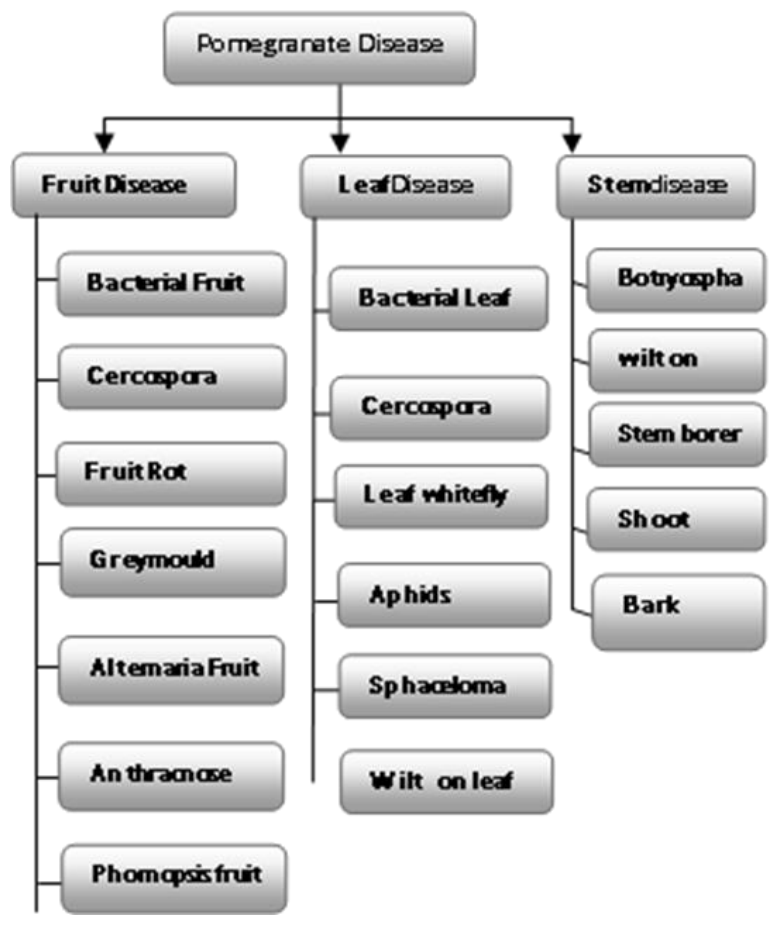

Fig. 1 Pomegranate Plant Diseases

\section{Pomogranate Plant Fruit Diseasae Detection Steps Using Image Processing Techniques}

Plant leaf detection systems follows following generic steps for leaf detection systems.

1. Pomegranate fruit image Acquisition

2. Preprocessing techniques for diseased fruit

3. Fruit segmentation with respect to disease sections

4. Retrieving interest disease section from fruit segments.

5. Extracting features from the fruit segment

6. Disease prediction using classification techniques.

\subsection{Pomegranate fruit Image Acquisition}

Pomegranate plant fruit image acquisition includes three ways: reflective mode imaging, Emissive imaging and transmissive imaging. This image capturing is usually carried out using image sensing devices such as cameras, radar, infrared, X-Ray, ultrasound or computer generated. After capturing this image is converted into digitization.

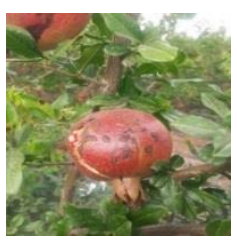

Bacterial Blight

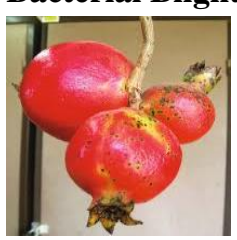

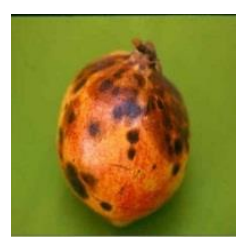

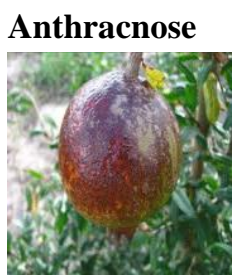

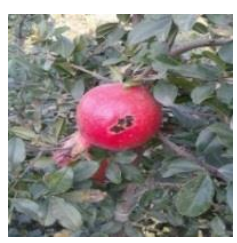

Cercospora

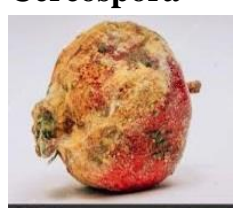

\section{Alternaria \\ Fruit rot \\ Fruit mold}

Fig. 2. Pomegranate Diseases. Source of Images [2]

\subsection{Preprocessing techniques for diseased fruit}

Preprocessing techniques are used to improve the quality of captured image. In this steps remove noise caused by dust, dewdrops, insect be present on the plant.

In image enhancement enhance the whole image or enhance interested region of the image. Image restoration in this process we are trying to restore blur or missing part of the image in further processing. This preprocessing step includes normalizing the intensity, removing background noise, masking portion of image, contrast improvement, image resizing, image smoothing, brightness enhancement, Histogram equalization and shadow removal activities etc.

\subsection{Fruit segmentation with respect to disease sections}

Fruit Image is split into different regions is called segment. Region based techniques. In segmentation mask the interested pixels in the image. In fruit disease detection most of the researchers used three techniques K-means clustering, Fuzzy C-means and Thresholding.

$\mathrm{K}$-means clustering: In k-means clustering image is divide in to k-clusters. According to the future set k-means algorithm classify the image pixel in to $\mathrm{k}$ clusters. Initially randomly select the cluster centroid. "During classification minimizing the sum of distance squares between the data objects and the corresponding k cluster. Euclidean distance is used to measure the distance between observed value and centroid value of clustered" [3].

$\sqrt{(X o-X c) 2+(Y o-Y c) 2}$

Fuzzy C-means: it is soft clustering. In case of fuzzy c means allow the pixel point in more than cluster. In Fuzzy c means assign membership node to each cluster.

Algorithm:

Step 1: initializing the data point randomly.

Step 2: find out the centroid of data point following equation.

Step 3: find out the distance between observed value and centroid value.

Step 4: Updating the membership value.

Step 5: repeat the step 2 and 4 until the forming constant cluster.

Thresholding: Thresholding is segmentation technique used for converting foreground and background. In some image has dark background and light object. In this case retrieve the object from dark background.This thresholding technique are used for converting grayscale image into binary image. There are two types of thresholding applied for image segmentation depending upon application. 


\section{Algorithm:}

Step I: Select the initial element for threshold T.

Step II: whole image is segment using $T$

A1 is all the pixels with intensities $>\mathrm{T}$

A2 is all the pixels with intensities $<=T$

Step III: compute average $\mathrm{p} 1$ and $\mathrm{p} 2$ for the pixels in

A1 and A2

Step IV: Let $\mathrm{T}=(\mathrm{p} 1+\mathrm{p} 2) / 2$

Step V: Repeat the step 1 and 4 until constant cluster will form.

Different segmentation techniques are applied for locate object and their boundaries

\subsection{Retrieving interest disease section from fruit segments.}

After segmentation of image next step is retrieving interest disease section. Extracted infected part of disease on fruit. In this step future selection and feature extraction techniques are applied. In fruit image futures usually consist of morphology, color, shape, texture, spatial and wavelet transformation. Morphology is one of the most important feature in image classification and feature retrieving. Accuracy of classification is highly depend on which feature set extracted from fruit image.

\subsection{Extracting the Feature from fruit segment}

"Feature extraction is the process of deriving a set of values called features from an image, which provides information about the image for further processing."[4]

Different feature extraction techniques used to extract features in infected disease segment of plant leaf, stem and fruit. Feature extraction methods applied on infected region of fruit disease image are GLCM, GLRM, standard deviation, entropy, variance, smoothness, skewness, kurtosis, contrast, fuzzy c-means and k-means.

\subsection{Disease prediction using classification techniques}

In this step assigning Pixels in the image to categories or classes of interest. Classify a set of data into different classes. Classification is done by two methods supervised learning and unsupervised learning. There are many image classification techniques used for plant disease detection. All these classifier tested using combination of various features extracted by feature extraction techniques. Most commonly used classification techniques for classifying pomegranate fruit diseases are SVM, ANN, KNN, PNN, Minimum distance classifier. The SVM classifier achieve highest accuracy 98.5\%. When you multiclassifier techniques some of the author apply KNN,SVM and PNN classifier with fuzzy cmeans for disease classification this achieved $99 \%$ accuracy. The 99\% accuracy is achieved closed capturing system, with high resolution camera is used. There is need of fusion of more than one feature extraction technique will achieved

\section{Comparative Anyalysi Pomegranate Fruit Disease Detection Using Various Soft Computing Techniques}

Fruit horticulture is backbone of every country. According to annual report of APEDA Maharashtra is leading state production of Pomegranate. Now a day's Indian farmer facing problem of fruit disease. "In pomegranate common fruit diseases are Bacterial Blight, Alternaria, Cercospora fruit rot, fruit rot, fruit borer, fruit mold. In India main reason of decreasing production of pomegranate is bacterial blight disease (Telya in Marathi)."[1] In this oily dark brown spot scattered on fruit. Fruit spot disease caused by fungi symptoms on fruit is light brown spot patches in fruit. Fruit rot actually this disease occurs on flowering stages they fails the process conversion of flowering to fruit. New young fruit drop on the plant. Early disease detection is essential so farmer can easily prevent theses disease at primary stage of infection. This disease detection achieved by image processing techniques.

Table 1: comparative analysis of image processing techniques applied on pomegranate fruit disease detection technique.

\begin{tabular}{|l|l|l|l|l|l|l|l|}
\hline Sr.no & Ref & Fruit Disease & Preprocessing & Segmentation & \multicolumn{1}{|c|}{$\begin{array}{l}\text { Feature } \\
\text { Extraction }\end{array}$} & Classification & Accuracy \\
\hline 1 & {$[5]$} & $\begin{array}{l}\text { Bacterial } \\
\text { diseases }\end{array}$ & $\begin{array}{l}\text { resize, } \\
\text { filtering, } \\
\text { morphological } \\
\text { operations, }\end{array}$ & K-means & $\begin{array}{l}\text { HCI color model, } \\
\text { erosion dilation } \\
\text { operation for } \\
\text { morphology, } \\
\text { Gabor filter for } \\
\text { texture feature }\end{array}$ & $\begin{array}{l}\text { Minimum } \\
\text { distance } \\
\text { classifier } \\
\text { (MDC). }\end{array}$ & $\begin{array}{l}\text { Not } \\
\text { specified }\end{array}$ \\
\hline 2 & {$[6]$} & $\begin{array}{l}\text { Bacterial } \\
\text { Blight }\end{array}$ & image resizing & Not specify & $\begin{array}{l}\text { Color Coherence } \\
\text { Vector feature } \\
\text { vectors SVM }\end{array}$ & $82 \%$ \\
\hline
\end{tabular}




\begin{tabular}{|c|c|c|c|c|c|c|c|}
\hline 3 & [7] & $\begin{array}{l}\text { Fruit rot, Fruit } \\
\text { spot, Bacterial } \\
\text { Blight }\end{array}$ & $\begin{array}{l}\text { Removing } \\
\text { noise }\end{array}$ & K-means & GLCM & $\begin{array}{l}\text { Back- } \\
\text { propagation } \\
\text { algorithm }\end{array}$ & $90 \%$ \\
\hline 4 & [8] & $\begin{array}{l}\text { Bacterial } \\
\text { Blight }\end{array}$ & $\begin{array}{l}\text { removes noise, } \\
\text { smoothen the } \\
\text { image also } \\
\text { perform } \\
\text { resizing of } \\
\text { images }\end{array}$ & K-means & Not Specify & $\begin{array}{l}\text { Calculating } \\
\text { plant leaf area } \\
\text { and diseased } \\
\text { area on leaf }\end{array}$ & $\begin{array}{l}\text { Not } \\
\text { specified }\end{array}$ \\
\hline 7 & [9] & $\begin{array}{l}\text { Anthracnose, } \\
\text { Bacterial } \\
\text { Blight, Scab }\end{array}$ & $\begin{array}{l}\text { background is } \\
\text { removed using } \\
\text { thresholding }\end{array}$ & $\begin{array}{ll}\text { Fuzzy } & \mathrm{C} \\
\text { means } & \end{array}$ & $\begin{array}{l}\text { fuzzy } \mathrm{C} \text { mean and } \\
\mathrm{K} \text { means }\end{array}$ & $\begin{array}{l}\text { KNN, PNN and } \\
\text { SVM } \quad \text { with } \\
\text { Fuzzy C Means }\end{array}$ & $99 \%$ \\
\hline 8 & {$[10]$} & Anthracnose & $\begin{array}{l}\text { Canny edge } \\
\text { detector and } \\
\text { Median filter }\end{array}$ & K-menas & $\begin{array}{l}\text { GLCM } \\
\text { GLRM }\end{array}$ & $\begin{array}{l}\text { Nearest } \\
\text { Neighbor and } \\
\text { Euclidian } \\
\text { distance }\end{array}$ & $94.85 \%$ \\
\hline 9 & [11] & $\begin{array}{l}\text { Bacterial } \\
\text { Blight, } \\
\text { Alternaria and } \\
\text { Scab }\end{array}$ & $\begin{array}{l}\text { contrast } \\
\text { enhancement }\end{array}$ & $\begin{array}{l}\text { fuzzy } \mathrm{C} \text { mean } \\
\text { and } \mathrm{K} \text { means }\end{array}$ & $\begin{array}{l}\text { fuzzy } \mathrm{C} \text { mean and } \\
\mathrm{K} \text { means }\end{array}$ & $\begin{array}{l}\text { KNN, PNN and } \\
\text { SVM classifier }\end{array}$ & $98.3 \%$ \\
\hline 10 & [12] & $\begin{array}{l}\text { Cercospora, } \\
\text { Bacterial } \\
\text { Blight, } \\
\text { Alternaria }\end{array}$ & $\begin{array}{l}\text { contrast } \\
\text { enhancement }\end{array}$ & K-means & $\begin{array}{l}\text { standard } \\
\text { deviation, } \\
\text { entropy, variance, } \\
\text { smoothness, }\end{array}$ & SVM & $\begin{array}{l}\text { Not } \\
\text { pecified }\end{array}$ \\
\hline 11 & [13] & $\begin{array}{l}\text { Scab, } \\
\text { Bacterial } \\
\text { Blight, } \\
\text { Anthracnose }\end{array}$ & $\begin{array}{l}\text { Gaussian low } \\
\text { pass channel, } \\
\text { Resizing }\end{array}$ & Not Specifed & $\begin{array}{l}\text { standard } \\
\text { deviation, } \\
\text { entropy, variance, } \\
\text { smoothness, } \\
\text { skewness, } \\
\text { kurtosis, contrast }\end{array}$ & $\begin{array}{l}\text { KNN, PNN and } \\
\text { SVM classifier }\end{array}$ & $\begin{array}{l}\text { KNN- } \\
84.84 \% \\
\text { PNN-80\% } \\
\text { SVM- } \\
54.54 \%\end{array}$ \\
\hline 12 & [14] & $\begin{array}{l}\text { Bacterial } \\
\text { Blight, } \\
\text { Alternaria }\end{array}$ & $\begin{array}{l}\text { Removing } \\
\text { noise }\end{array}$ & K-means & $\begin{array}{l}\text { Color and texture } \\
\text { features are } \\
\text { extracted }\end{array}$ & BPNN classifier & $97.30 \%$ \\
\hline 13 & {$[15]$} & $\begin{array}{l}\text { bacterial } \\
\text { blight, wilt, } \\
\text { thrip, fruit } \\
\text { borer and scab }\end{array}$ & $\begin{array}{l}\text { Image resized } \\
\text { to } 400 * 400\end{array}$ & K-Means & $\begin{array}{l}\text { Morphology, } \\
\text { color and CCV }\end{array}$ & $\begin{array}{l}\text { Multi-class } \\
\text { Support Vector } \\
\text { Machine }\end{array}$ & $84 \%$ \\
\hline 14 & {$[16]$} & $\begin{array}{l}\text { Bacterial } \\
\text { Blight, Fruit } \\
\text { rot, } \\
\text { Anthronous }\end{array}$ & $\begin{array}{l}\text { Histogram } \\
\text { equalization. }\end{array}$ & Not Specified & $\begin{array}{l}\text { Spatial and } \\
\text { Wavelet features } \\
\text { extracted } \\
\text { wavelet transform } \\
\text { (DWT) is used for } \\
\text { feature extraction }\end{array}$ & $\begin{array}{l}\text { SVM training } \\
\text { and Testing and } \\
\text { Feed Forward } \\
\text { Artificial Neural } \\
\text { Network }\end{array}$ & $\begin{array}{l}\text { SVM } \\
76.483 \% \\
\text { ANN } \\
92.65 \%\end{array}$ \\
\hline
\end{tabular}

This section presents a survey of 16 papers of pomegranate fruit disease detection including criteria such as pomegranate diseases name, Pre-processing, Segmentation, Feature Extraction, classification and accuracy. Table 1 presents the comparative analysis of image processing techniques applied on pomegranate fruit disease detection. Generally, to identify the disease from a fruit one of the most important thing is dataset. In case of pomegranate no standard dataset is available. All the dataset is created by own by capturing healthy and unhealthy fruit images from farmer 
field. At each step of image processing steps author applied different techniques out of which most of the author applied SVM classifier. SVM classifier gives better result. K-Means clustering techniques is widely applied for segmentation. "Fuzzy C means segmentation technique gives highest accuracy. Some of the author classify the data using multiple classifier SVM, KNN, PNN" [9]. Classification accuracy is depends upon which feature set extracted from infected region. There is need of fusion of one and more future extraction techniques applied on extracting features in disease interested area.

\section{Discussion And Summary}

This review articles summarizes various pomegranate disease detection and classification techniques. The literature survey shows extensive computer vision techniques in pomegranate disease detection there so immense of research in this area is possible in future.

Here are some points for future research to boost current state of art.

- Most of the research on disease detection was done manually collected database. The lack of availability of dataset remains a major challenge for enabling vision based plant disease detection. The few existing databases are either too limited or not accessible to the scientific community. There is a need to develop standard dataset for Pomegranate disease detection.

- $\quad$ Sometime two disease present on same fruit or Different disorders with similar symptoms challenging to identify investigate one or more diseases in same fruit accurately along with the stage of the disease.

- The research conducted till date with available techniques detects few diseases only. There is need to develop techniques which identify and classify recent pomegranate fruit disease therefore study number of more diseases.

- $\quad$ Some of the existing system uses manual dataset every disease having different stages Different stages having different symptoms. No one yet detect different stages of disease and exact solution of those diseases.

- Most of the existing systems are semi-automatic. There is need to develop fully automated system with collaboration of agriculture universities and research centers for upgrading the system with new diseases and checking the disease detection accuracy.

- A real time system for Pomegranate plant disease detection is not yet proposed in the existing literature. Need of exploring algorithms for image segmentation, fusion of more than one disease feature extraction selection methods to improve the output of the proposed method.

Copyright $($ C Authors
- There is need to develop decision support system/app which will easily and widely available to farmer, just by capture the plant query image of fruit captured by sensor devices and send it to the DSS system. DSS system detect the plant diseases at initial stages of infection provide plant treatments prescribed by the decision support system.

- Existing plant disease detection system having limitations in terms of techniques, size of database, captured image quality, disease symptoms varies according to variety of pomegranate plant

\section{Conclusion}

In this paper, we present a review of pomegranate plant disease detection using image processing techniques. From literature during feature extraction color, texture and morphology features are used to identify and classify the pomegranate fruit diseases. Among these techniques morphological features gives best result as compared to all other features. SVM and ANN, KNN, PNN classifier used to detect bacterial and fungal and viral diseases in fruit of pomegranate. K-means clustering for image segmentation Fuzzy c means gives highest accuracy. In existing system very few diseases are covered. There are need to cover maximum disease which are existing in pomegranate fruit. This paper is helpful for the study of existing system and work on research gaps finding and development of new technology for pomegranate fruit and plant disease. This will helpful for pomegranate farmers to increase the yield. Most of the existing systems are semi-automatic. There is need to develop fully automated system with collaboration of agriculture universities and research centers for upgrading the system with new diseases.

\section{References}

[1] Pawar, R., \& Jadhav, A. (2017, September). Pomegranate disease detection and classification. In 2017 IEEE International Conference on Power, Control, Signals and Instrumentation Engineering (ICPCSI) (pp. 2475-2479). IEEE. http://vikaspedia.in/agriculture/crop-production.

[2] Dhanashree Gadkari, "Image quality analysis using glcm", Thesis, University of Central Florida, Orlando, Florida, 2000.

[3] Bharate, A. A., \& Shirdhonkar, M. S. (2017, December). A review on plant disease detection using image processing. In 2017 International Conference on Intelligent Sustainable Systems (ICISS) (pp. 103-109). IEEE.

[4] Khot, S. T., Supriya, P., Gitanjali, M., \& Vidya, L. (2016). Pomegranate disease detection using 
image processing techniques. Pune, International Journal of Advanced Research in Electrical, Electronics and Instrumentation Engineering.

[5] Bhange, M., \& Hingoliwala, H. A. (2015). Smart farming: Pomegranate disease detection using image processing. Procedia Computer Science, 58, 280-288.

[6] Dhakate, M., \& Ingole, A. B. (2015, December). Diagnosis of pomegranate plant diseases using neural network. In 2015 fifth national conference on computer vision, pattern recognition, image processing and graphics (NCVPRIPG) (pp. 1-4). IEEE.

[7] Deshpande, T., Sengupta, S., \& Raghuvanshi, K. S. (2014). Grading \& identification of disease in pomegranate leaf and fruit. International Journal of Computer Science and Information Technologies, 5(3), 4638-4645.

[8] Shivanand B Lamani, Ravikumar K, Arshi Jamal (2018) . Pomegranate Fruits Disease Classification with Fuzzy C Mean ClusteringInternational Journal of Advance Engineering and Research Development(IJAERD) Volume 5, Issue 02, February -2018.

[9] Pujari, J. D., Yakkundimath, R., \& Byadgi, A. S. (2015). Image processing based detection of fungal diseases in plants. Procedia Computer Science, 46, 1802-1808.

[10] Noola, D. (2018). Disease Identification of Pomegranate Fruit using Image Processing. Asian Journal For Convergence In Technology (AJCT), 4(3).

[11] Mr. Dharmesh Dhabliya, Mr. Rahul Sharma. (2012). Efficient Cluster Formation Protocol in WSN. International Journal of New Practices in Management and Engineering, 1(03), 08 - 17.

[12] Gaikwad, D., Karande, K., \& Deshpande, H. (2016, December). Pomegranate Fruit Diseases Identification and Grading. In International Conference on Communication and Signal Processing 2016 (ICCASP 2016). Atlantis Press.

[13] Purvimath, M. K., \& Patil, P. B. POMEGRANATE FRUIT DISEASE DETECTION AND CLASSIFICATION.

[14] Sannakki, S. S., \& Rajpurohit, V. S. (2015). Classification of pomegranate diseases based on back propagation neural network. International Research Journal of Engineering and Technology (IRJET), Vol2, (02).

[15] More, S., \& Nighot, M. (2016, March). Agrosearch: A web based search tool for pomegranate diseases and pests detection using image processing. In Proceedings of the Second International Conference on Information and Communication Technology for Competitive Strategies (pp. 1-6).

[16] Kumar, A., Rajpurohit, V. S., \& Jirage, B. J. (2018). Pomegranate fruit quality assessment using machine intelligence and wavelet features. Journal of Horticultural Research, 26(1), 53-60. 